\title{
AVALIAÇÃO SAZONAL DA PRODUÇÃO DE BORRACHA E DA DINÂMICA DE CARBOIDRATOS SOLÚVEIS EM PLANTAS DE SERINGUEIRA (Hevea brasiliensis Müll. Arg.) CULTIVADAS EM LAVRAS, MINAS GERAIS ${ }^{1}$
}

\author{
Denis Ubeda de Lima², Luiz Edson Mota de Oliveira ${ }^{3}$, Ângela Maria Soares ${ }^{3}$ e Nelson Delú-Filho ${ }^{3}$
}

\begin{abstract}
RESUMO - O objetivo deste trabalho foi avaliar a produção de látex de seringueira (Hevea brasiliensis) e as possíveis alterações no teor de carboidratos em função das variações de fatores climáticos. Foram utilizadas plantas do clone RRIM 600 com 8 anos de idade e no primeiro ano de exploração. As análises dos teores de açúcares solúveis totais e açúcares redutores foram realizadas em duas datas distintas, 29/8/97 (inverno) e 23/12/ 97 (verão), com amostragens em intervalos de 3 horas, em um ciclo de 24 horas de avaliação. A produção de borracha seca foi avaliada em duas sangrias, em cada estação. Os resultados evidenciaram que, além da relação da produção de borracha com a disponibilidade de água, as variações de temperatura entre as estações também tiveram uma importante influência sobre a disponibilidade de carboidratos para a síntese de látex.
\end{abstract}

Palavras-chave: Seringueira, carboidratos, produção de látex e fatores climáticos.

\section{SEASONAL EVALUATION OF LATEX YIELD AND SOLUBLE SUGAR DYNAMICS IN RUBBER TREES (Hevea brasiliensis Müll. Arg.) CULTIVATED IN LAVRAS, MG}

\begin{abstract}
The objective of this work was to evaluate the latex yield from rubber tree (Hevea brasiliensis) and the effects of variation of climatic factors on carbon metabolism. Data were collected from 8-year-old RRIM 600 rubber tree clone in the first tapping year, cultivated at the experimental area of the Biology Department of the Federal University of Lavras. Analyses of soluble and reducing sugar contents was performed in two distinct dates, 8/29/97 (winter) and 12/23/97 (summer), with samples being taken at 3 h intervals during 24 hours. Dry rubber yield was evaluated by two tappings performed in each period. The results suggest that, besides the relationship between latex yield and soil water status, the temperature variation from such period also had an important influence on carbon metabolism, mainly the carbohydrate availability for latex synthesis.
\end{abstract}

Key words: $\quad$ Rubber tree, sugar, latex production, climatic factors.

\section{INTRODUÇÃO}

Em virtude da grande demanda por borracha natural e dos aspectos fitossanitários, a seringueira vem sendo cultivada em condições edafoclimáticas distintas de seu habitat natural, e ainda assim tem apresentado um bom desenvolvimento vegetativo, mesmo em regiões como o sul de Minas Gerais, onde o inverno é marcado pela ocorrência de baixas temperaturas e por um baixo índice pluviométrico. Essa diversidade nas características climáticas, além dos aspectos edáficos, solicita o desenvolvimento de estudos que comprovem a viabilidade da

1 Recebido para publicação em 5.12.2000.

Aceito para publicação em 20.6.2002.

Financiado pela FAPEMIG.

2 Eng.-Agr., M.S. em Fisiologia Vegetal, Instituto de Botânica da Universidade Estadual de Campinas - UNICAMP, Caixa Postal 4005, 01061-970 Campinas-SP. ${ }^{3}$ Prof. Dr. do Setor de Fisiologia Vegetal, Dep. de Biologia da Universidade Federal de Lavras - UFLA, Pesquisador IB/CNPq, Caixa Postal 37, 37200-000 Lavras-MG. 
implantação da heveicultura nessa região, gerando tecnologias mais apropriadas de cultivo e exploração. Portanto, os estudos ecofisiológicos têm um importante papel quando analisam a influência de fatores ambientais, como temperatura e pluviosidade, sobre a produção de borracha e sobre alguns fatores relacionados à biossíntese do látex.

As mudanças verificadas nos fatores ambientais durante as diferentes estações envolvem variações de luz, temperatura, umidade do ar e disponibilidade de água no solo. Essas variações afetam as trocas gasosas e o metabolismo de carboidratos e, conseqüentemente, influenciam a produção de borracha ao longo do ano. Em alguns trabalhos têm sido avaliado os efeitos de fatores edafoclimáticos sobre o crescimento das plantas de seringueira e a produção de látex (Paardekooper \& Samosorn, 1969; Carretero, 1984; Devakumar et al., 1988; Lemos Filho et al., 1993; Nugawela et al., 1995). No entanto, raramente são estudados os efeitos de fatores ambientais sobre processos fisiológicos relacionados ao metabolismo do carbono, envolvendo síntese, transporte e utilização de carboidratos, e sua relação com a produção de borracha, principalmente em regiões onde as estações são bem definidas, diferindo do habitat natural da seringueira.

O objetivo deste trabalho foi avaliar alguns efeitos dos fatores ambientais (precipitação média diária, umidade relativa, insolação, temperaturas máxima e mínima) na produção de borracha e sobre os teores de açúcares solúveis totais (AST) e açúcares redutores (AR), em plantas de seringueira cultivadas em Lavras-MG.

\section{MATERIAL E MÉTODOS}

O presente estudo foi conduzido na área experimental do Departamento de Biologia da Universidade Federal de Lavras-MG. A área com seringueira foi implantada em outubro de 1989, quando sete clones de seringueira foram plantados em espaçamento tradicional de cultivo comercial $(7,0 \times 2,5 \mathrm{~m})$. Para realização deste estudo foi selecionado o clone RRIM-600, por sua representatividade econômica e por, normalmente, apresentar uma boa produção de borracha.

Os dados climáticos foram obtidos da Estação Climatológica Principal de Lavras, Minas Gerais, situada a uma latitude de $21^{\circ} 14^{\prime} \mathrm{S}$, longitude de $45^{\circ} 00^{\prime} \mathrm{W}$ e altitude de $910 \mathrm{~m}$, localizada a cerca de $300 \mathrm{~m}$ da área experimental. No Quadro 1 estão os valores médios de alguns fatores ambientais dos meses referentes às avaliações e os valores referentes aos dias avaliados.

As análises de AST e AR foram realizadas em extratos de lâminas foliares e de tecidos de casca do caule das plantas estudadas. Os folíolos foram coletados em intervalos de 3 horas, durante 24 horas, tendo seis repetições amostradas em cada avaliação. As avaliações foram realizadas em dias claros, sendo retiradas folhas do terço superior das copas das árvores, em torno de $6 \mathrm{~m}$ de altura, uma vez que essas folhas estão mais correlacionadas com a produção de látex (Nugawela \& Aluthhewage, 1990). Os tecidos analisados de casca foram os mesmos retirados durante o processo de sangria. Cada planta representou uma parcela, totalizando assim cinco repetições em cada época. Os materiais coletados foram congelados em nitrogênio líquido e armazenados em freezer a $-86^{\circ} \mathrm{C}$, até o momento das análises.

As metodologias utilizadas para quantificação dos AR e AST foram as descritas por Yemm \& Willis (1954) e M üler (1959), respectivamente. Os tecidos foram homogeneizados em um meio de extração composto de tampão fosfato de potássio $0,1 \mathrm{M} \mathrm{pH} 7,5, \mathrm{MgCl}_{2} 0,5 \mathrm{M}$, EDTA 0,1 M, DTT 1,0 M, PMSF 0,4 M e PVPP na proporção de $1 \mathrm{~g}$ tecido $/ 5 \mathrm{ml}$ extrator. Seguiu-se uma centrifugação a $30.000 \mathrm{~g}$ durante 10 minutos, a $4{ }^{\circ} \mathrm{C}$, do sobrenadante foram retiradas alíquotas para determinações analíticas.

A produção de borracha foi mensurada em plantas cujos painéis foram abertos em março de 1997, quando elas se apresentavam com mais de $45 \mathrm{~cm}$ de circunferência do tronco a $1,20 \mathrm{~m}$ da superfície do solo. As sangrias foram realizadas às 6 horas (horário solar), tendo sido adotado o sistema de explotação em meio espiral (S/2), em uma inclinação de corte de $35^{\circ}$, com duas sangrias por semana, espaçadas de três e quatro dias $(\mathrm{D} / 3 \mathrm{e}$ $\mathrm{D} / 4$ ). Estimulou-se a produção por meio da aplicação de $1 \mathrm{ml}$ de Ethrel (2,5\%) por canaleta, a cada dois meses. Após cada sangria misturaram-se ao látex $2 \mathrm{ml}$ de ácido acético diluído (vinagre), para auxiliar na sua coagulação. $\mathrm{O}$ látex coagulado foi submetido à secagem em estufa ( $70^{\circ} \mathrm{C}$ até peso constante) e, posteriormente, pesado. Os valores de produção foram apresentados em gramas de borracha seca por planta por sangria (g bs.pl/sangria), obtidos pela média de duas sangrias realizadas em cinco plantas. No inverno as sangrias foram realizadas nos dias 21 e 30 de agosto e no verão, nos dias 22 e 30 de dezembro. 


\section{RESULTADOS E DISCUSSÃO}

\subsection{Produção de Borracha}

Observa-se no Quadro 1 que o mês de agosto caracterizou-se por ser mais seco, em função da falta de chuvas, mantendo desta forma uma umidade relativa média inferior à de dezembro. Os valores médios mostram ainda que a temperatura mínima em agosto também foi menor do que em dezembro, caracterizando, portanto, um período mais frio. Analisando uma seqüência de cinco a dez dias antecedentes aos dias 29/8 e 23/12, verificou-se (dados não mostrados) que esses períodos apresentaram uma média nos fatores climáticos semelhante às médias mensais, o que justificou a escolha dessas datas para representar os respectivos meses e as respectivas estações, inverno e verão.

Observa-se (Figura 1) que a produção média de borracha em agosto foi de $8,5 \mathrm{~g}$ bs.pl/sangria, aumentando significativamente $(\mathrm{P}<0,01)$ para $17,5 \mathrm{~g}$ bs.pl/sangria, em dezembro. Essas produções estão abaixo dos valores médios encontrados nas regiões tradicionais de cultivo de seringueira. Deve-se ressaltar, porém, que os valores encontrados neste trabalho foram referentes ao primeiro ano de sangria, que normalmente apresenta menores produções.

A maior produção de borracha em dezembro indica que os fatores ambientais ocorrentes nos diferentes períodos, especificamente as chuvas e temperaturas médias mais elevadas, afetaram o fluxo e a biossíntese de látex, como será discutido posteriormente.

\subsection{Açúcares Redutores e Açúcares Solúveis Totais}

Analisando a Figura 2, observa-se que ao longo dos dias avaliados a evolução dos teores foliares de AR e
AST foi semelhante para uma mesma época, o que indica que a utilização dos açúcares redutores nos processos metabólicos depende da disponibilidade dos açúcares totais. Os teores máximos de AST e AR, observados em agosto, foram verificados às 6 horas, seguindo-se uma queda nos níveis ao longo do dia (Figura 2a e 2c). No verão, verificou-se tendência de aumento nos teores entre 6 e 18 horas (Figura $2 b$ e $2 d$ ), o que evidencia, nesse período, uma resposta diretamente correlacionada à temperatura do ar (Quadro 2). Nota-se que esses teores de carboidratos solúveis não são repostos com a mesma eficiência, possivelmente devido à baixa taxa fotossintética no mês de agosto, em função das baixas

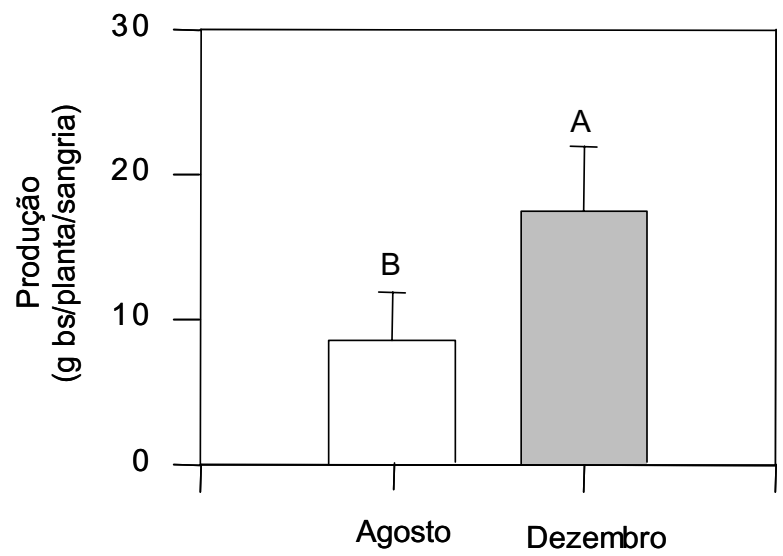

Figura 1 - Produção de borracha do clone RRIM 600 durante os períodos de agosto e dezembro. Médias seguidas pela mesma letra não diferem entre si pelo teste $\mathrm{F}$, a $1 \%$ de probabilidade. As barras referem-se aos desviospadrão.

Figure 1 - Latex production of clone RRIM 600 from August to December. Mean values followed by the same letter did not differ by the F test at $1 \%$ of probability. The bars refer to standard deviation.

Quadro 1 - Valores médios diários de precipitação, umidade relativa média do ar, insolação e temperatura máxima e mínima referentes aos meses de agosto e dezembro de 1997, nos dias de avaliação (29/08 e 23/12), obtidos na Estação Climatológica Principal de Lavras

Table 1 - Rainfall average, air relative humidity average, insolation, maximum and minimum temperature data during August and December 1997 and the evaluation days (08/29 and 12/23), obtained from Main Weather Station of Lavras

\begin{tabular}{|l|c|c|c|c|c|c|c|c|c|c|}
\hline & \multicolumn{2}{|c|}{$\begin{array}{c}\text { Precipitação } \\
\text { Média Diária } \\
(\mathrm{mm})\end{array}$} & $\begin{array}{c}\text { Umidade Relativa } \\
\text { Média } \\
(\%)\end{array}$ & \multicolumn{2}{|c|}{ Insolação } & \multicolumn{2}{c|}{$\begin{array}{c}\text { Temperatura } \\
\text { Máxima } \\
(\mathrm{h})\end{array}$} & \multicolumn{2}{c|}{$\begin{array}{c}\text { Temperatura } \\
\text { Mínima } \\
\left({ }^{\circ} \mathrm{C}\right)\end{array}$} & \multicolumn{2}{c|}{\begin{tabular}{c}
$\left.{ }^{\circ} \mathrm{C}\right)$ \\
\cline { 2 - 11 }
\end{tabular}} & Ago. & Dez. & Ago. & Dez. & Ago. & Dez. & Ago. & Dez. & Ago. & Dez. \\
\hline Média Mensal & 0,0 & 8,2 & 55,2 & 78,3 & 9,0 & 6,4 & 28,4 & 29,0 & 11,1 & 18,8 \\
\hline Dia Avaliado & 0,0 & 0,0 & 41,0 & 61,0 & 10,5 & 11,7 & 30,4 & 32,8 & 10,9 & 19,0 \\
\hline
\end{tabular}


temperaturas. O elevado nível de carboidratos observados às 6 horas da manhã na primeira avaliação reforça essa hipótese, considerando que esses carboidratos seriam produtos da hidrólise de amido armazenado nas folhas das plantas de seringueira. Entretanto, no verão o aumento no teor de AST e AR está associado à maior taxa fotossintética, em relação ao mês de agosto.

Os teores de AST e AR nas lâminas foliares mostraram variações significativas entre as épocas de avaliação (Figura 3). Possivelmente, o carbono assimilado durante a estação mais fria poderia estar sendo incorporado em compostos insolúveis, como o amido, uma vez que a translocação estaria também reduzida pela baixa disponibilidade de água. Normalmente, quando as plantas encontram-se com boa disponibilidade hídrica o teor de sacarose tende a aumentar bastante nas folhas, visto ser esse o principal carboidrato transportado no floema de plantas superiores, o que corrobora com os dados apresentados no Quadro 3.

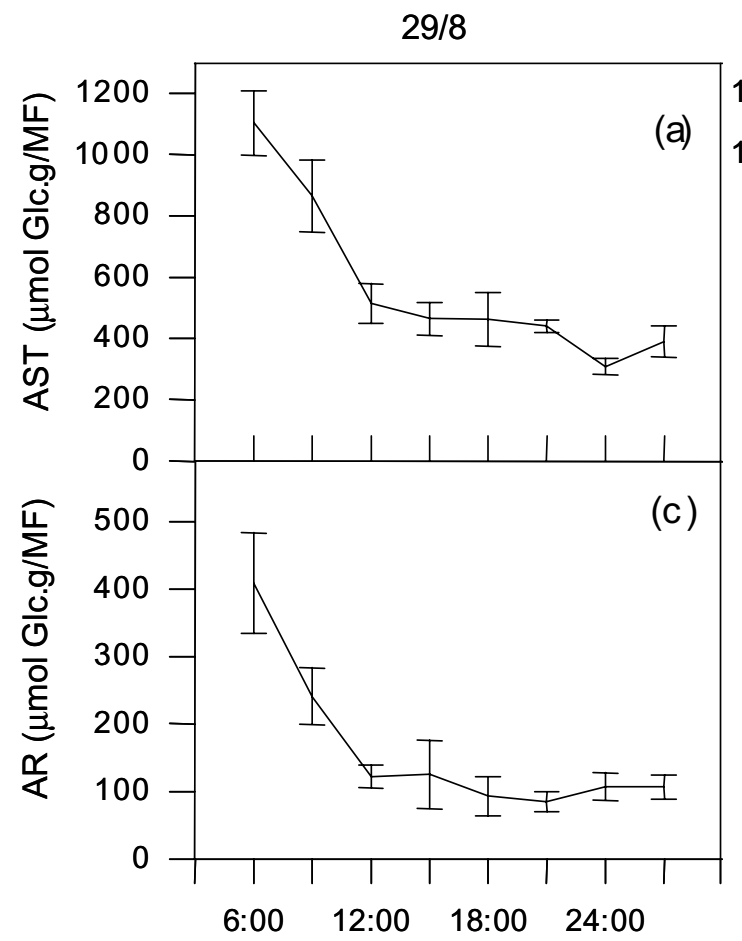

Quadro 2 - Variação num ciclo de 24 horas na temperatura do ar durante os dias de avaliações. A temperatura foi obtida com um termômetro colocado próximo às copas das árvores

Table 2 - Air temperature variation in a 24 hour cycle during evaluation days. Temperature was determined with a thermometer placed close to the tree canopies

\begin{tabular}{|c|c|c|}
\hline \multirow{2}{*}{ Horário } & \multicolumn{2}{|c|}{ Temperatura do $\operatorname{Ar}\left(^{\circ}\right)$} \\
\cline { 2 - 3 } & $29 / 8$ & $23 / 12$ \\
\hline 6 horas & 10,0 & 22,5 \\
9 horas & 25,0 & 37,0 \\
12 horas & 28,5 & 34,0 \\
15 horas & 30,0 & 33,0 \\
18 horas & 24,0 & 25,0 \\
21 horas & 19,0 & 21,0 \\
24 horas & 16,0 & 19,0 \\
3 horas & 13,0 & 18,0 \\
\hline
\end{tabular}

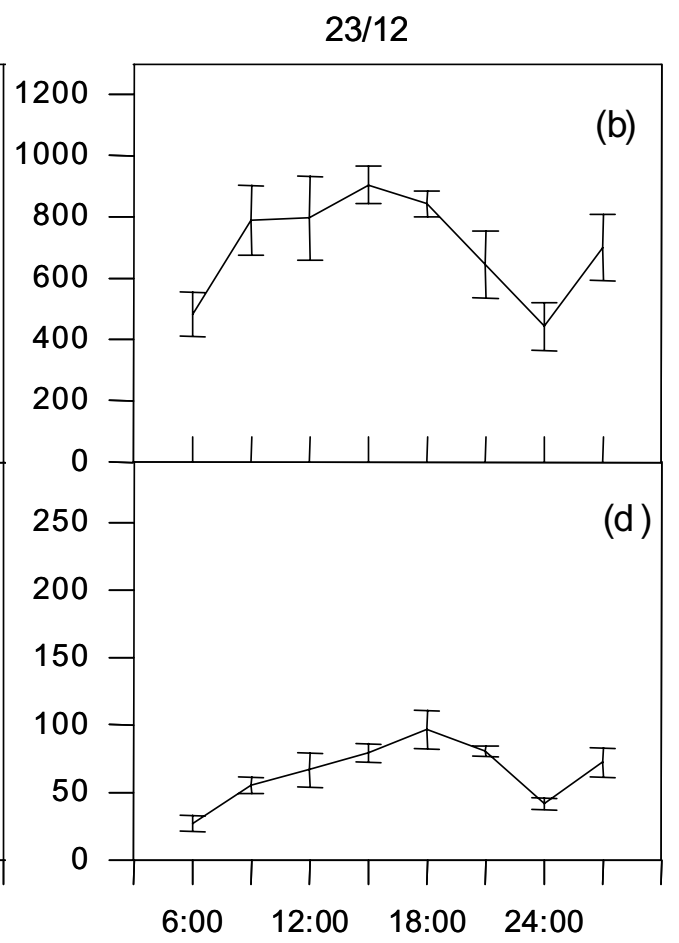

\section{Hora Solar}

Figura 2 - Evolução em um ciclo de 24 horas dos teores de açúcares redutores (AR) e açúcares solúveis totais (AST), em lâminas foliares de plantas de seringueira, para as avaliações de 29/8 (inverno) e 23/12 (verão). As barras referem-se aos desvios-padrão.

Figure 2 - Evolution in a 24 hour cycle in reducing sugar (RS) ant total soluble sugar (TSS) levels, for the winter (8/29) and summer (12/23) evaluations. The bars refer to standard deviation. 

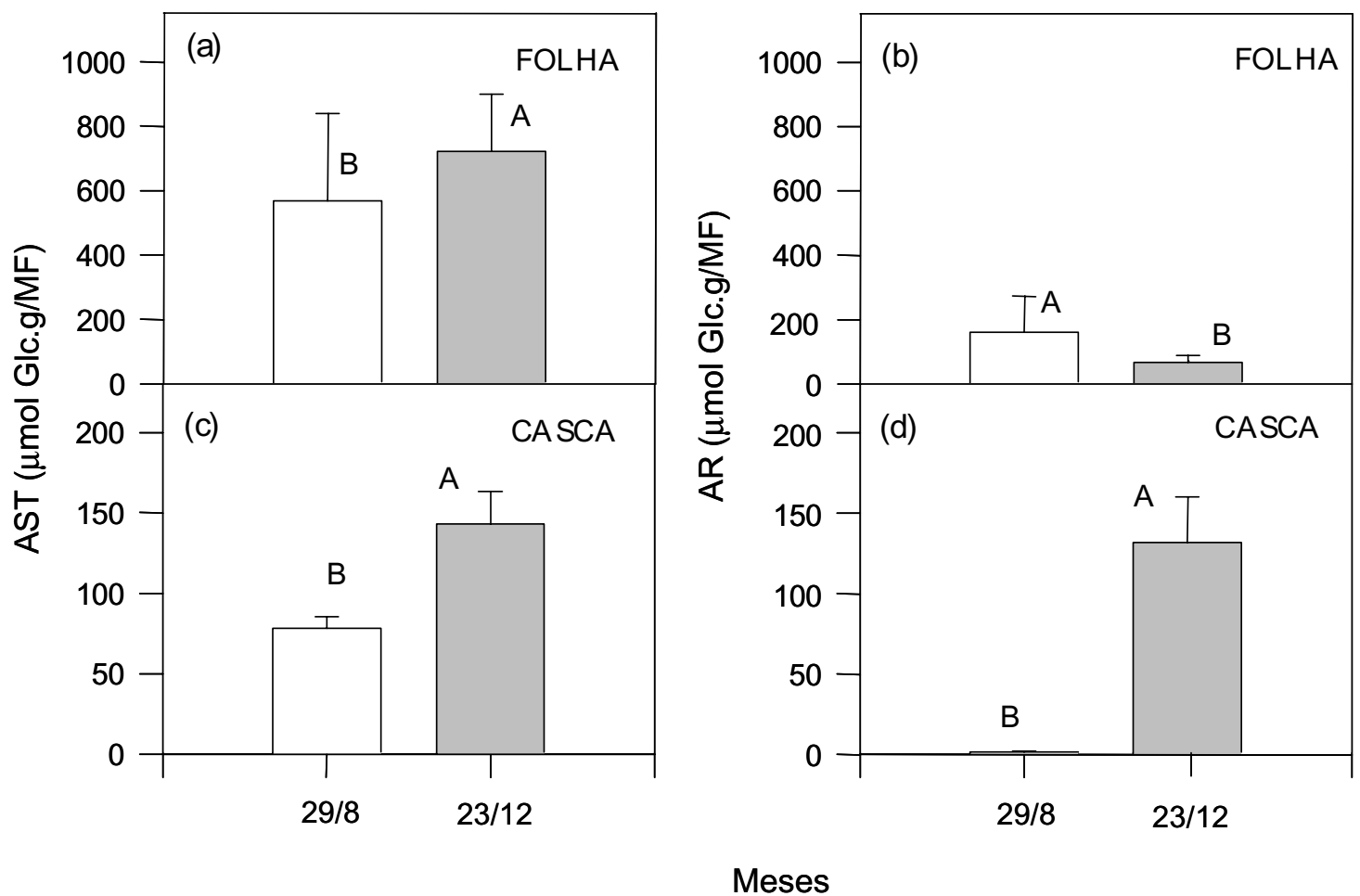

Figura 3 - Teores médios de açúcares solúveis totais (AST) e açúcares redutores (AR) para os tecidos da folha e da casca de plantas de seringueira, analisados em duas datas distintas (29/8 e 23/12). Médias seguidas pela mesma letra não diferem entre si pelo teste $\mathrm{F}$, a $1 \%$ de probabilidade. As barras referem-se aos desvios-padrão.

Figure 3 - Total soluble sugar (TSS) and reducing sugar (RS) mean levels in leaf and external trunk tissues, analyzed on two distinct dates (8/29 and 12/23). Means followed by the same letter did not differ by the $F$ test at $1 \%$ of probability. The bars refer to standard deviation.

Quadro 3 - Estimativas da disponibilidade de sacarose nos diferentes tecidos (folha e casca), analisada em duas datas (29/8 e 23/12), obtidas através da diferença entre os valores médios de açúcares solúveis totais e açúcares redutores (AST-AR)

Table 3 - Sucrose availability estimate in different tissues (leaf and bark), analyzed on two dates (8/28 and 12/29) obtained through the difference between mean values of total soluble sugars and reducing sugars (TSS-RS)

\begin{tabular}{|l|c|c|}
\hline Data & $\begin{array}{c}\text { Folha } \\
(\mu \mathrm{mol} \mathrm{Glc} / \mathrm{g} \text { MF })\end{array}$ & $\begin{array}{c}\text { Casca } \\
(\mu \mathrm{mol} \mathrm{Glc} / \mathrm{g} \mathrm{MF})\end{array}$ \\
\hline $29 / 8$ & 366,5 & 68,9 \\
$23 / 12$ & 589,6 & 10,4 \\
\hline
\end{tabular}

$\mathrm{Na}$ casca, os teores de AST e AR foram maiores em dezembro $(\mathrm{P}<0,01)$, época em que as condições climáticas, como maior ocorrência de chuvas e menor amplitude térmica, pareceram favoráveis ao maior acúmulo e à translocação dos açúcares dos tecidos foliares para esse dreno (Figura 3c e 3d). Os tubos laticíferos, que são compostos por células especializadas na síntese do látex, são encontrados em maior densidade justamente nos tecidos da casca de seringueira, daí serem considerados um dreno potente.

A biossíntese do látex envolve uma seqüência de reações que pode, em termos simplificados, ser dividida em duas fases: 1) o catabolismo de glicídeos, por meio da glicólise, transformando sacarose em acetato; e 2) a síntese do isopentenil difosfato, unidade base da policondensação em borracha (Pujade-Renaud et al., 1994). Analisando a primeira fase da biossíntese, observa-se que o suprimento de sacarose nos tubos laticíferos e a velocidade de sua utilização, dada pela hidrólise catalisada pela invertase, são fatores limitantes no metabolismo e na produção de borracha (Tupy, 1985; Condurú Neto, 1987; Castro, 1990).

Nas avaliações realizadas no tecido da casca durante o inverno (29/8), observou-se que os AST constituíramse quase que exclusivamente de açúcares não-redutores 
(sacarose), uma vez que a quantidade de açúcares redutores foi quase nula nesse tecido (Quadro 3 e Figura 3c e $3 d$ ). Os altos teores de sacarose observados nos tecidos laticíferos da casca podem indicar baixa atividade da invertase, provavelmente devido às menores temperaturas verificadas em agosto. Conseqüentemente, a produção de hexoses oriundas da hidrólise da sacarose seria diminuída, levando à menor produção de borracha nesta época (Figura 1). A capacidade hidrolítica da invertase em tecidos de folhas e de colmo de cana-de-açúcar mostrouse máxima à temperatura de $42^{\circ} \mathrm{C}$. A $17^{\circ} \mathrm{C}$, por exemplo, a atividade invertásica atingiu cerca de $20 \%$ de seu valor máximo (Oliveira, 1985). Tal resultado indica que as baixas temperaturas de agosto (observar que as análises foram realizadas em tecidos coletados às 6 horas da manhã, com temperatura próxima a $10^{\circ} \mathrm{C}$ ), associadas à ausência de chuvas, podem ter sido determinantes na atividade da invertase nos tecidos laticíferos da casca das plantas de seringueira. Há indícios também de que a enzima citossólica sintase da sacarose é um importante ponto de regulação na hidrólise da sacarose em alguns tecidos-dreno (Delú-Filho et al., 2000).

Analisando os tecidos da casca coletados em 23/12 (Figura 3), observa-se que a quase totalidade dos AST foi composta de açúcares redutores, correspondente ao baixo teor de sacarose nessa avaliação (Quadro 3), o que indica que a sua hidrólise pela invertase seria intensa, levando à maior disponibilidade de hexoses para a rota glicolítica e, conseqüentemente, possibilitando a maior produção de borracha por planta (Figura 1).

Yeang et al. (1984) verificaram que nos meses de inverno houve acentuada redução na atividade da invertase, associada ao aumento no índice de obstrução, que correlaciona o fluxo inicial de látex e sua quantidade total escoada. Conseqüentemente, verificou-se queda na produção de borracha. Portanto, a atividade da invertase é correlacionada negativamente à facilidade de obstrução dos tubos laticíferos e positivamente com a produção (Tupy, 1973). Em Chethackal, Índia, durante a estação seca, a menor produção de borracha mostrou-se associada ao alto índice de obstrução de escoamento de látex e ao seu baixo fluxo inicial. Menores taxas de transpiração foliar e turgescência nos tubos laticíferos também foram observadas durante este período (Devakumar et al., 1988).

Os fatores climáticos em dezembro, especificamente temperaturas médias mais elevadas e maior ocorrência de chuvas, possivelmente foram os que mais favoreceram a maior disponibilidade de açúcares prontamente assimiláveis (redutores) nos tecidos laticíferos, podendo estar relacionados com a maior produção de borracha. Mais estudos devem ser realizados para verificar a influência desses fatores climáticos sobre as atividades enzimática da invertase e da sintase da sacarose, nos tecidos laticíferos da casca.

\section{REFERÊNCIAS BIBLIOGRÁFICAS}

CARRETERO, M. V. Efeitos de fatores climáticos e de clones de seringueira na produção de látex em PariqueraAçu e Campinas. Piracicaba: Escola Superior de Agricultura "Luiz de Queiroz", 1984. 51 p. Tese (Doutorado em Solos e Nutrição de Plantas) - Escola Superior de Agricultura "Luiz de Queiroz", 1984.

CASTRO, P. R. C. Bases fisiológicas da produção e da estimulação de Hevea brasiliensis. In: BERNARDES, M. S. (Ed.) Sangria da seringueira. Piracicaba: Escola Superior de Agricultura "Luiz de Queiroz"/Universidade e São Paulo, 1990. p. 1-25.

CONDURÚ NETO, J. M. H. Fatores limitantes e parâmetros fisiológicos da produção da seringueira. Belém: Faculdade de Ciências Agrárias do Pará, 1986. 20 p.

DELÚ-FILHO, N. et al. A sucrose binding protein homologue from soybean affects sucrose uptake in suspension-cultured transgenic tobacco cells. Plant Physiology and Biochemistry, v. 38, n. 5, p. 353-361, 2000.

DEVAKUMAR, A. S. et al. Studies on soil-plantatmosphere system in Hevea: II. Seasonal effects on water relations and yield. Indian Journal of Natural Rubber Research, v. 1, p. 45-60, 1988.

LEMOS FILHO, J. P.; PINTO, H. S.; ROCHA NETO, O. G. Responses of Hevea brasiliensis Muell. Arg. plants to low temperatures under controlled conditions. International Journal of Biometeorology, v. 37, p. 203-206, 1993.

MÜLLER, G. L. Use of dinitrosaliciylic acid reagent for determination of reducing sugar. Analytical Biochemistry, v. 31, p. 426-428, 1959.

NUGAWELA, A.; ALUTHHEWAGE, R. K. The effect of tapping on the $\mathrm{CO}_{2}$ assimilation rates of Hevea brasiliensis Muell. Arg. leaves. Journal of Rubber Research Institute of Sri Lanka, v. 70, p. 45-51, 1990.

NUGAWELA, A.; ARIYAWANSA, P.; SAMARASEKERA, R.K. Physiological yield determinants of sun and shade leaves of Hevea brasiliensis Muell. Arg. Journal of Rubber Research Institute of Sri Lanka, v. 76, p. 1-10, 1995. 
OLIVEIRA, L. E. M. Comportamento fisiológico de plantas de cana-de-açúcar (Saccharum sp.) sob condições de deficiência hídrica: alterações da assimilação do nitrato e mobilização de açúcares. Campinas: Universidade Estadual de Campinas, 1985. 126 p. Tese (Doutorado em Ciências) - Universidade Estadual de Campinas, 1985.

PAARDEKOOPER, E. C.; SAMOSORN, S. Clonal variation in latex flow pattern. Journal of Rubber Research Institute of Malaya, v. 21, p. 264-273, 1969.

PUJADE-RENAUD, V. et al. Ethylene-induced increase in glutamine synthetase activity and mRNA levels in Hevea brasiliensis latex cells. Plant Physiology, v. 105, p. 127132, 1994.
TUPY, J. The activity of latex invertase and latex production in Hevea brasiliensis Muell. Arg. Physiologie Végetale, v. 11, p. 633-641, 1973.

TUPY, J. Some aspects of sucrose transport and utilization in latex producing bark of Hevea brasiliensis Muell. Arg. Biologia Plantarum, v. 34, n. 4, p. 51-64, 1985.

YEANG, H.Y. et al. A preliminary investigation into the relationship between latex invertase and latex vessel plugging in Hevea brasiliensis. Journal of Rubber Research Institute of Malaysia, v. 32, p. 50-62, 1984.

YEMM, E. W.; WILLIS, A. J. The estimation of carbohydrates in plant extracts by anthrone. The Biochemical Journal, v. 90 , n. 3, p. 508-514, 1954. 